\title{
TASHMIM AN NAMUDZAJ LI TA'LIM AL LUGHAH AL 'ARABIYAH AL ITTISHALIYAH
}

\author{
تصيميم النموذج لتعليم اللغة العربية الاتصالية
}

\author{
Rojja Pebrian \\ Universitas Islam Riau \\ rojjapebrian@fis.uir.ac.id
}

\begin{abstract}
The world today has witnessed a strong demand for learning the Arabic language whether in the Arab countries or the non-Arab countries and this language is gaining importance day by day. The teaching of Arabic has expanded throughout the world, and its educational approaches have expanded, including the communicative approach. The aim of this study is to present a proposed vision for teaching Arabic language through communicative approach. The researcher adopted the descriptive analytical method. The study concluded that the learning program of communicative Arabic language should has several things, including: the educational aspects of the implementation of pedagogy, the role of the teacher, the role of the learner and the role of subjects, focus skills, other interests like teaching time, information technology and environment, and good preparation of the Arabic language communication textbook.
\end{abstract}

\section{Keywords: Language teaching, communicative approach, textbook}

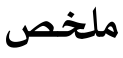

لقد شهد عالمنا الحاضر إقبالا شـيدا على تعلم اللغة العربية سواء كان في البلاد العربية أم في البلاد غير العربية، وتكتسب هذه اللغة أهمية يوما بعد يوم. لقد اتسع نطاق تعليم اللغة العربية في أرجاء المعمورة، وتعددت مداخل تعليمها، منها المدخل الاتصالي. تهدف هذه الدراسـإإلى تقديم تصورا مقترحا لتعليم اللغة العربية الاتصالية. واعتمد الباحث في إجراء الدراسة على المنهج الوصفي التحليلي، وتوصيّلت الدراسة إلى النتائج وهي أن يراعي برنامج تعليم اللغة العربية

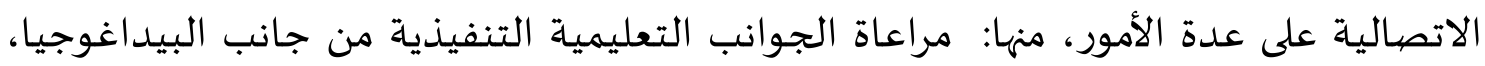
وجانب الدور الذي يتمثل في دور المعلم ودور المتعلم ودور المواد الدراسية، وجانب تركيز المهارات، واهتمامات أخرى من أوقات التدريس ووسائل المعلمومات والتكنولوجيا والبيئة، والاهتمام بإعداد كتاب تعليم اللغة العربية الاتصالية النموذجي. الكلمات المفتاحية: تعليم اللغة، المدخل الاتصالي، الكتاب المدرسي 
يؤكد علماء اللغة في أنّ الهدف الأساسي من تعليم اللغةإكساب المتعلم القدرة على الاتصال اللغوي الواضح والسليم، ولتحقيق ذلك فإن ثمّة مهارات أساسية للتواصل اللغوي، وهي: الاستماع، والتحدث، والقراءة، والكتابة، فهي مهارات لازمة، وضرورية لكل إنسان يستطيع

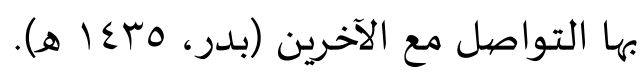
ولكن نتائج الدراسات السابقة تقول بأن إتقان المتعلمين للمهارات اللغة العربية الأربعة

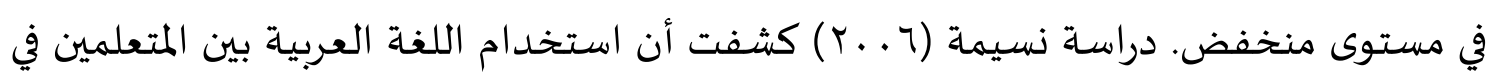

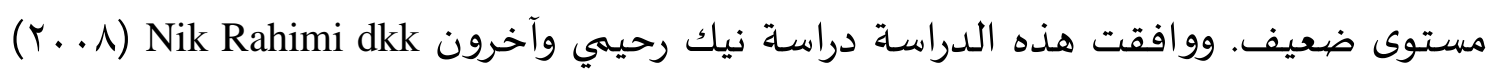
حيث بيّنت أن كفاءة المتعلمين اللغوية في مستوى ضعيف. وكشفت دراسة كمرول شكري وآخرون Kamarul Shukri المهارات اللغوية خاصة في التحدث والكتابة. بينما أظهرت نتائج دراسة كمرول زمان ونيك رحيهي

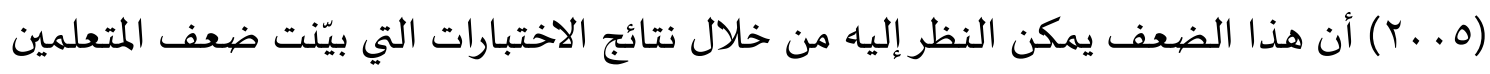
بصفة عامة في الكفائات اللغوية. والدراسـة التي أجرها عبد الرحمن (9 . . ب) حول العوائق التي

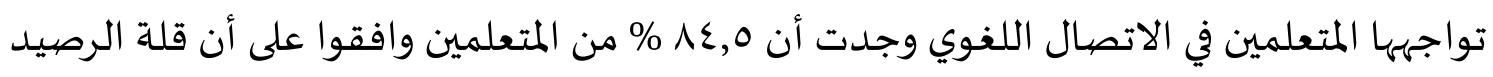
اللغوي أو المفرادات من العوائق الأسـاسية في التواصل باللغة العربية. والدراسـة التي أجراها علدين Aladin

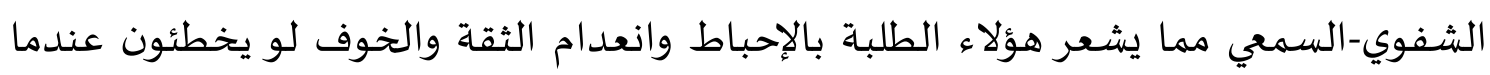

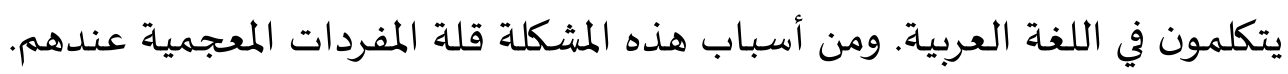
بناء على المشكلات التي ذكرناها تبين لنا أن برنامج تعليم اللغة العربية تواجه مشكلات كثيرة ما يحول دون نجاح عملية التعليم والتعلم. نتساءل إذن كيف نجري برنامج تعليم اللغة برتئ العبية النموذجي، الذي يحقق نجاح عملية التعليم والتعلم، بناء على المدخل الاتصالي؟ هذه الدراسة المتواضعة تحاول أن تجيب هذه القضية بإذن الله تعالى.

الإطار النظري

تعليم اللغة الاتصيالية (Communicative Language Teaching)

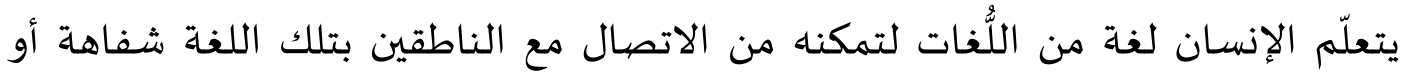
كتابة، فاللغة أداة لاتصال، وهي كما حدها ابن جني: " أصيوات يعبر بها كلُّ قوم عن أغراضههم"

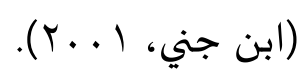


وأصبح تعليم اللغة الاتصالية الآن نموذجا مقبولا بالعديد من التفسيرات والمظاهر.

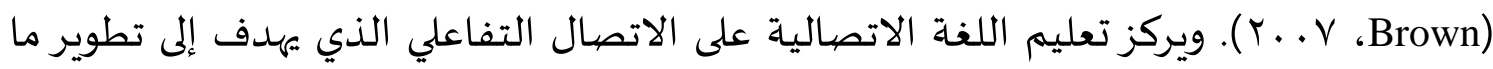

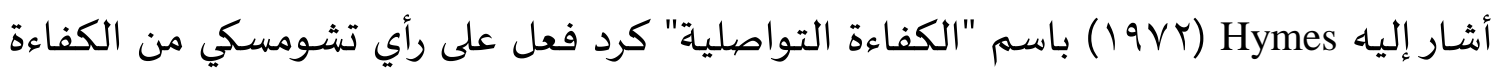
اللغوية، وعند الآخرين وهو يعني استخدام الإجراءات حيث يعمل الطلاب في أزواج أو جماعات

لتوظيف الموارد اللغوية المتاحة في حل مشكلة المهام. (Richards \& Rodgers، 1917 (19). وتعليم اللغة الاتصالية مدخل من مداحل تعليم اللغة (Richards \& Rodgers،

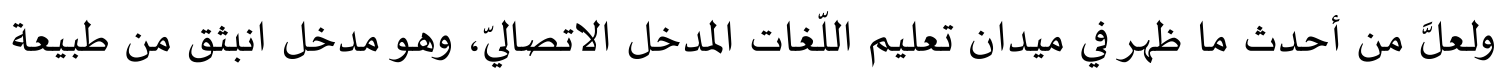
اللَّغة نفسها أي بوصفها وسيلة للاتِّهال أو التواصل بين البشر، وهذه الميزة هي التي ميّزت هذا المدخل عن غيره من المداخل التي طُبقت في تعليم اللُّات وتعلّمها. (طعيمة، ع. ع. . ب).

أهداف تعليم اللغة الاتصيالية ومبادؤها يهدف تعليم اللغة الاتصالية إلى (1) جعل الكفائة التواصلية الهدف من تدريس اللغة

(Y) تطوير إجراءات لتدريس المهارات اللغوية الأربعة (Richards \& Rodgers،

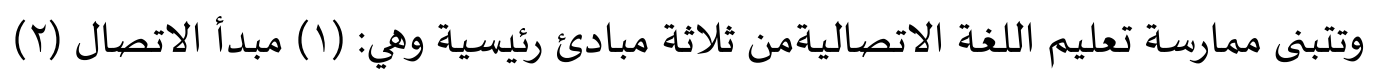
مبدأ المهمة (ץ) مبدأ معانٍ. (Richards \& Rodgers، 1917 (1). وهذه المبادئ تؤكد دور تفاعلي للاتصال. وتنعكس هذه الطبيعة التفاعلية للتواصل من خلال الطبيعة التعاونية من صنع معنى مثل إرسال أو استقبال الرسائل بين المتعلمين. (Savignon، (1991).

\section{خصائص تعليم اللغة الاتصهالية}

ذهب Littlewood (1911) إلى أناه يجب تطوير مهارات لغوية عند المتعلمين قبل تطوير الاختصاص الوظيفي، وأكّد أهمية دور الكفائة الاتصالية في مواقف الحياة الحقيقية. ووفقا لرأيه

$$
\text { يتضمن تعليم اللغة الاتصالية ست خصيائص: }
$$

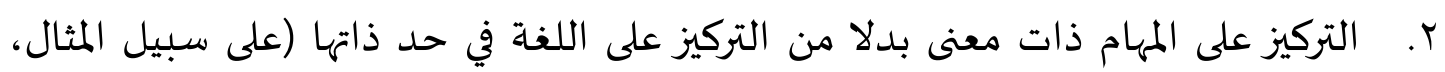

$$
\text { قواعد اللغة أو دراسة المفردات) }
$$

ז. الجهود لجعل المهام واللغة ذات صلة بالفئة المستهدفة من المتعلمين من خلال تحليل

$$
\begin{aligned}
& \text { حالات حقيقية وواقعية } \\
& \text { ع. استخدام أصيلة، من مواد الحياة الحقيقية وفية }
\end{aligned}
$$

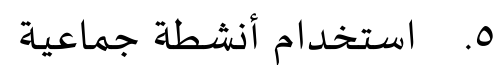




\section{دور المعلمين والمتعلمين في تعليم اللغة الاتصالية}

هناك ميزة أخرى لتعليم اللغة الاتصالية وهي محور التعلم والخبرة السابقة من تعليم

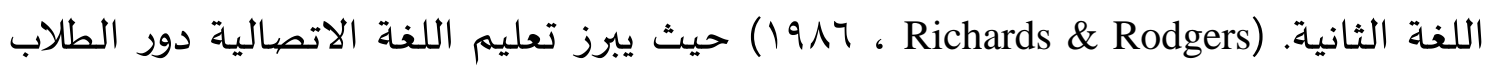
الفعال في الفصول الدراسية، والمعلمون هم أقل هيمنة في التعليم، والمعلمون في بعض الأحيان ميسرون أو مستشارون، وتارة أخرى أههم يمكن أن يكونواشركاء في التواصل. (Larson-Freeman،

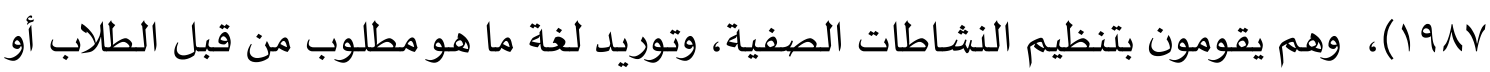

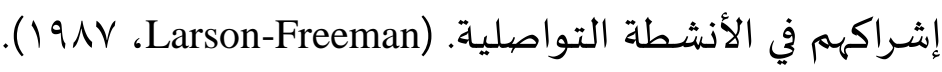

\section{الكفاءة اللغوية والكفاية الاتصبالية}

ومما يتعلق بتعليم اللغة اتصاليا ما يسهى بالكفاية اللغوية، والكفاية الاتصالية. وقد فرَّق طعيمة (ع . . Y) بين مصطلحي الكفاية اللغوية، والكفاية الاتصاليّة. فالكفاية اللغويّة عنده "يقصد بها أن الفرد يعرف النظام الذي يحكم اللغة، ويطبقه دون انتباه أو تفكير واع، كما أن لديا القدرة على التقاط المعاني اللغوية، والعقلة، والوجدانية، والثقافيّة التي تصحب الأشكال لهال

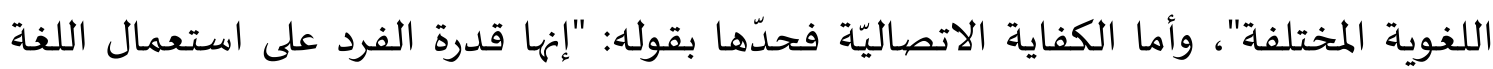
بشكل تلقائي مع توفر حسّ لغويّ يميز به الفرد بين الوظائف المختلفة للغة في مواقف الاستعمال الفعلي"ومما يتعلق بالتعلم الاتصالي ما يسمى بالكفاية الاتصالية. أما Brown (ع 199 1) فيرى أن تعريف كلٍّ من ميتشل كانل Michael Canals وميريل سوين Merril Swain

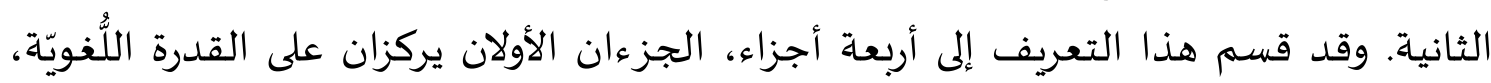

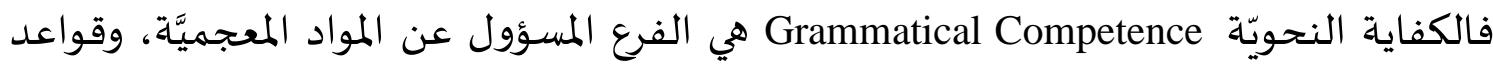

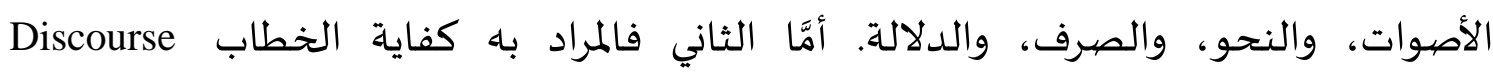
Competence اللغويّة بين الجمل. وذكر أنَّ الجزء الثالث من الكفايات هو الكفاية الاجتماعياة، وهي الأهم لارتباطها بمعرفة القواعد الاجتماعياة، والثقافية للغة الخطاب. وهنا تظهر أهمية السياق في التواصل، فهو الذي يجعل للحوارات مغزَّى ومعنى، ويقود إلى التفاعل. وأشـار Brown (ع 199 ) إلى

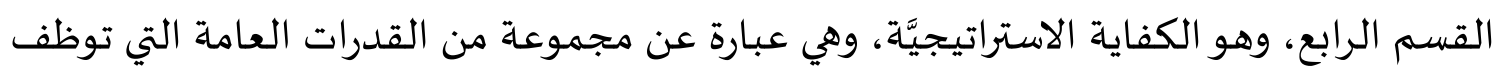
كلَّ عناصر الكفاية اللغوية (وكذلك المهارات الحركية) في عملية استخلاص المعنى. 
وتعبر الكفاءة اللغوية عن سيطرة الشخص على كافة أشكال الاتصال اللغوي في صورته المنطوقة والمكتوبة،فهي تعني القدرةعلى التواصل وإنتاج الكلام. وتتحقق هذه الكفاءة عندما يمتلك المتعلم المهارات الأسـاسية في فنون اللغة و هي الاستماع والتحدث والقراءة والكتابة

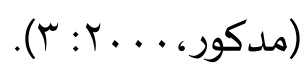

وفي مجال اللغات الأجنبية فإن الوصول بالمتعلم إلى مستوى الكفاءة اللغوية هو الغرض النهائي لبرامج التعليم، حيث تعكس الكفاءة اللغوية language proficiency مدى إجادة المتعلم

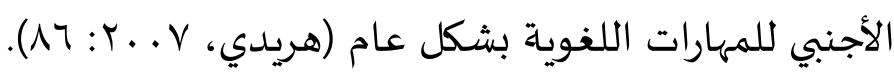
وللكفاءة اللغوية عدة مستويات، ولكل مستوى مؤشر يعبر عن مدى تمكن المتعلم من

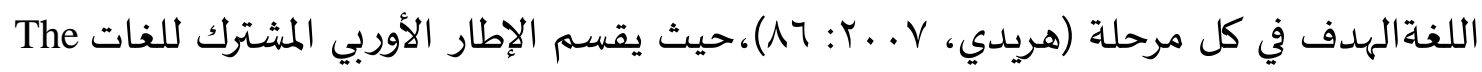
(إ) Common European Framework (CEF)

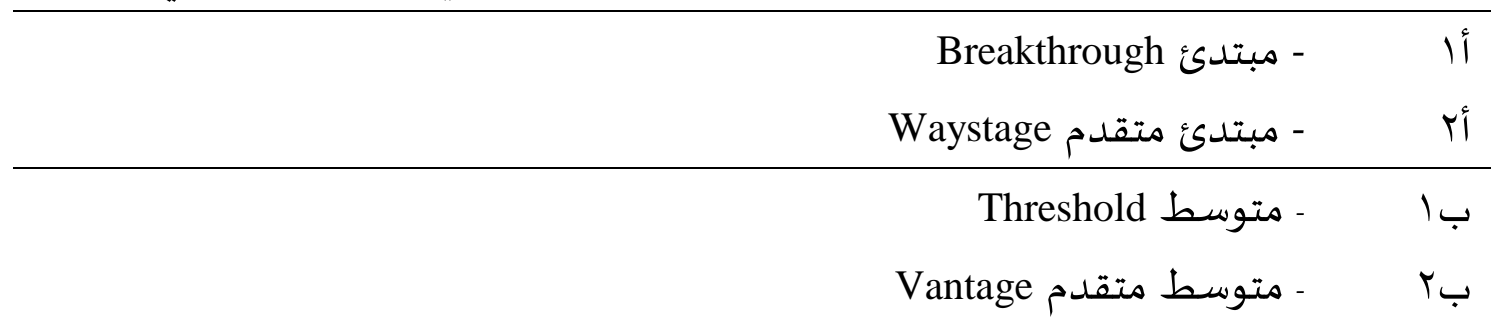

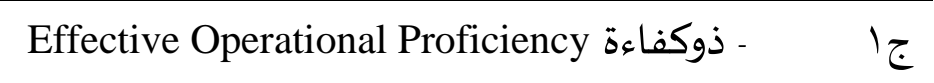

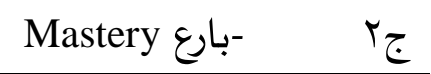

ويشير الإطار الأوربي المشترك للغات إلى أن هذه التقسيمات إنماهي تفرعات عليا و دنيا للتقسيم

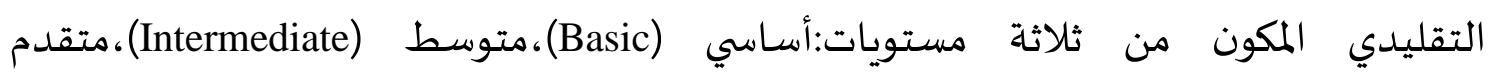
(Advanced)

\section{الأنشطة التواصلية}

ولقد قدم Brown ( . . . ( ) تصنيفا شاملا لتقنيات تعليم اللغة المشتركة تم تكييفاء من Crookes و Chaudron (199 ) ). ويستند هذا التصنيف على ثلاث فئات رئيسية هي: التحكم، شبه التحكم، والحر. وتم تجميع الأنشطة التواصلية الشفهية / السمعية تحت ثلاث فئات رئيسية؛

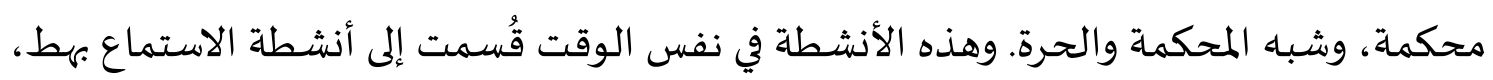
والأنشطة التي تدمج مهارات الاستماع والتحدث، وبالتالي، فإن هذه التصنيفات تتناسب مع

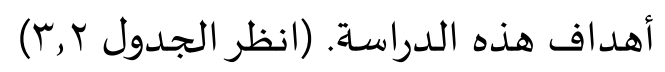


جدول ا أنشطة وتقنيات التواصل الشفوي- السمعي

\begin{tabular}{|c|c|c|}
\hline الأنشطة التي تدمج مهارات الاستماع & أنشطة الاسـتماع فقط & تقنيات \\
\hline 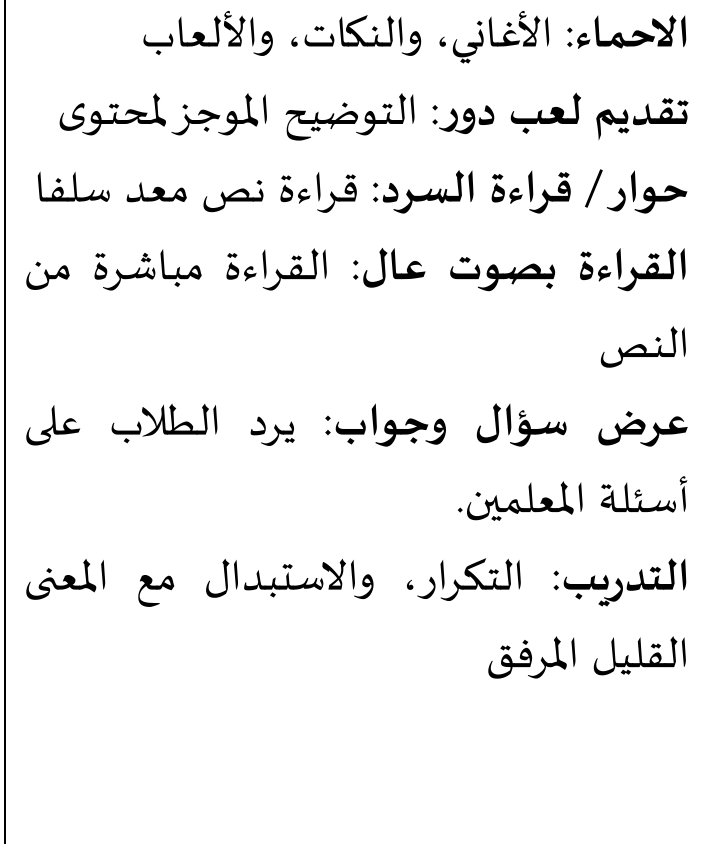 & 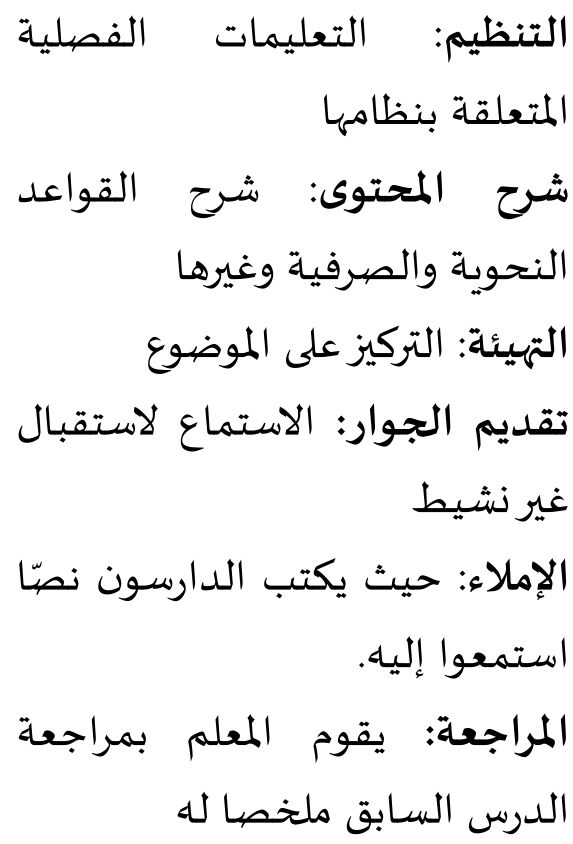 & التحنيات \\
\hline مالم التدريب بالمفهوم: استحجابة بختيارات ذات & 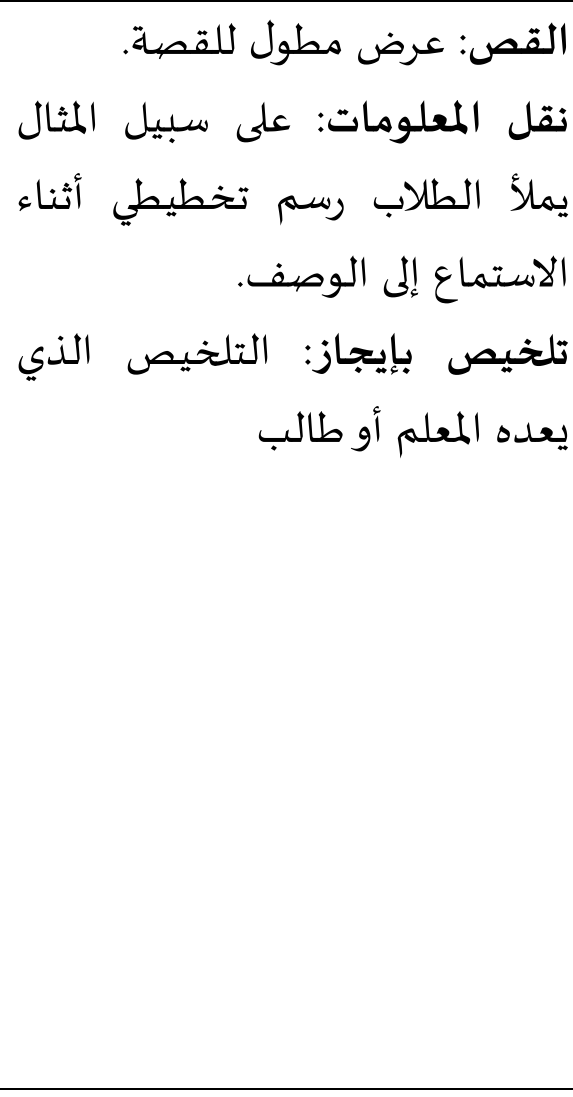 & تقنيات \\
\hline
\end{tabular}




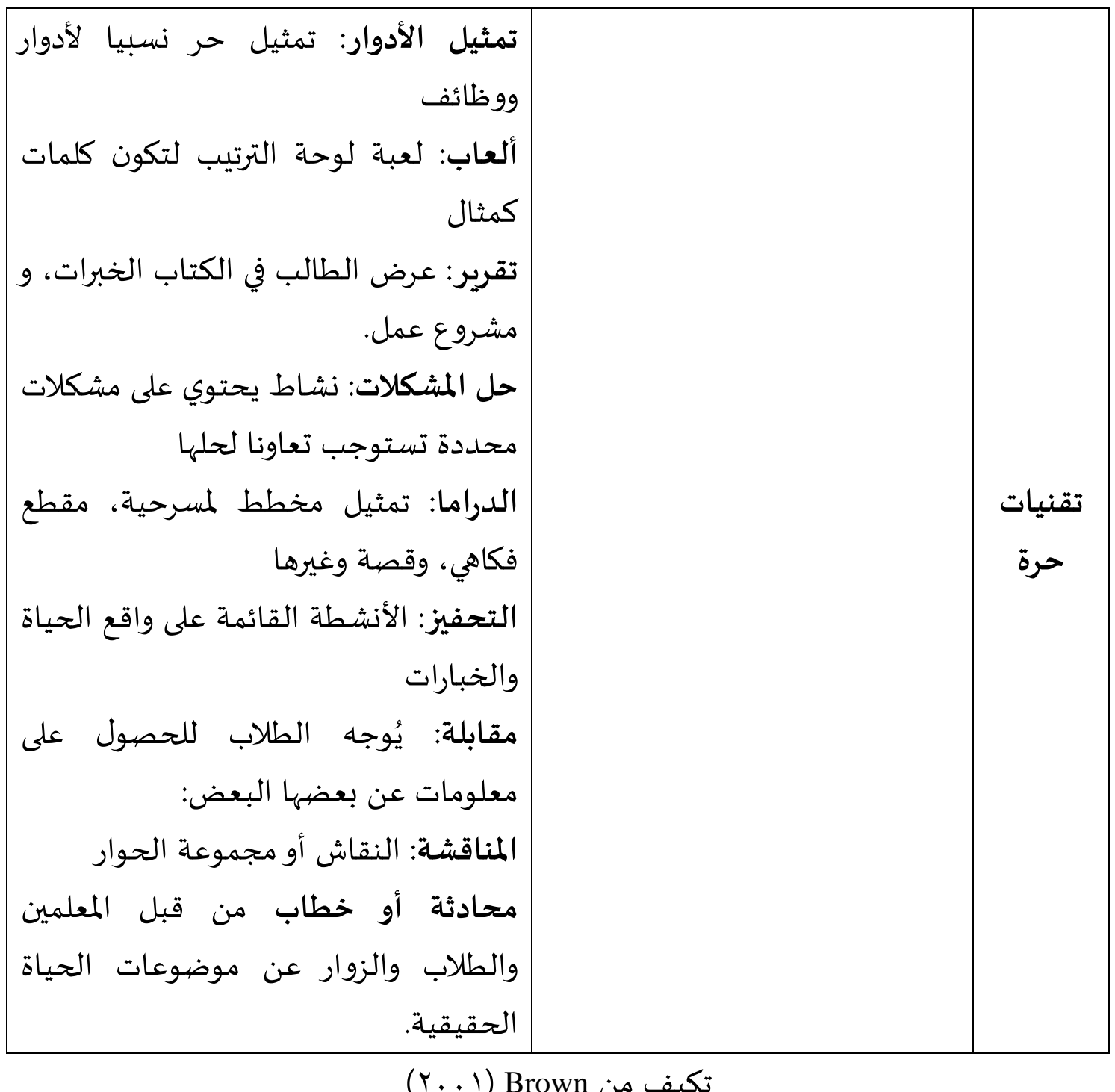

إعداد الكتاب المدرسي على ضوء المدخل الاتصالي

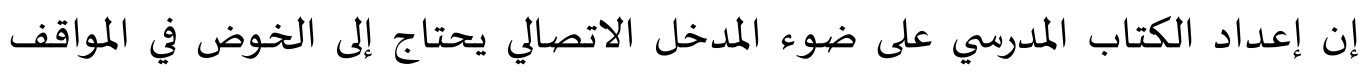

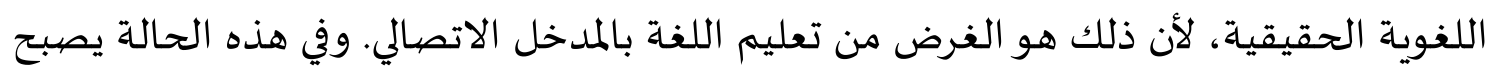

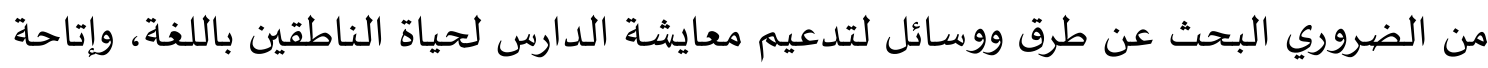

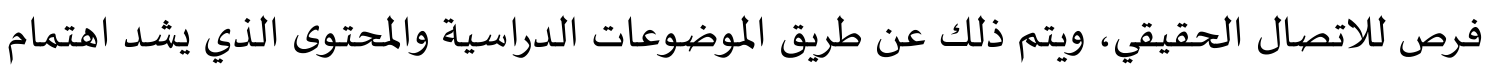

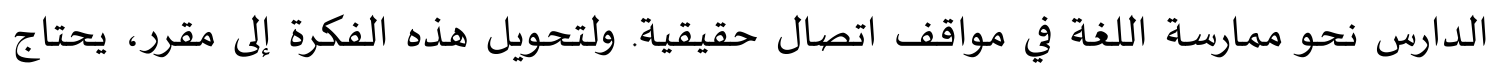

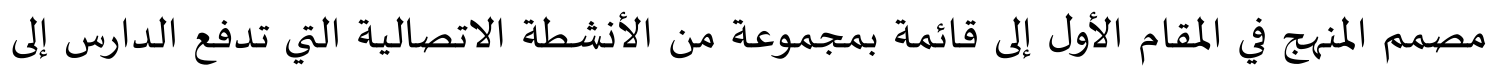

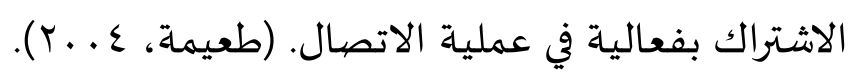


ولقد أشار Richards (Y . . إ) إلى كتاب تعليم اللغة الاتصالية ينبغي أن يوفر مواد

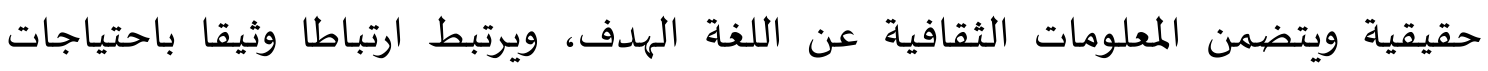

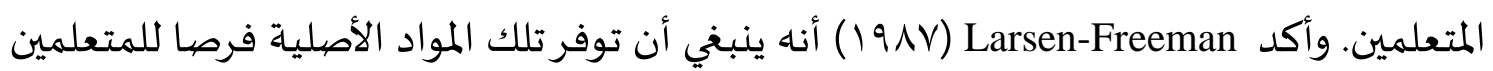
على تطوير استراتيجياتهم للتعامل مع اللغة كما تُستخدم بالفعل من قبل الناطقين بها. آنسا.

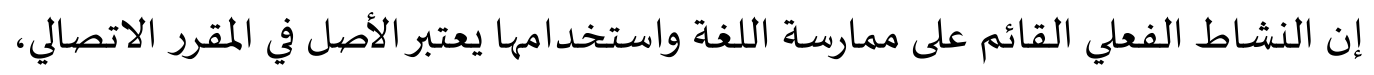

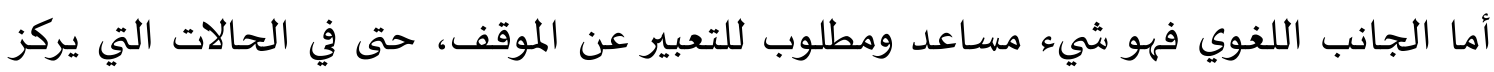

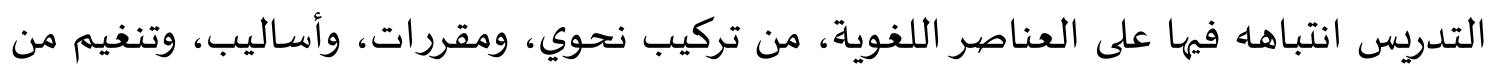

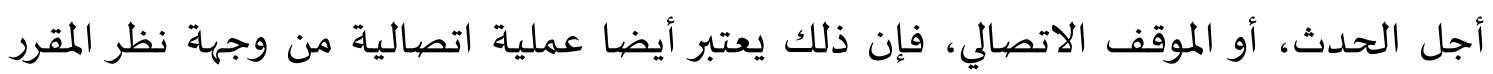

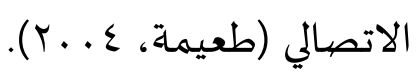

وأما Richards (0 . . Y: 10) فقال إذا كان تأليف الكتاب لغرص الاتصال ولتنمية الكفاءة

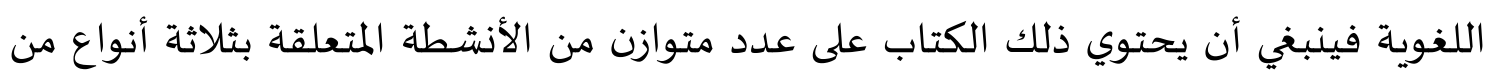
ممارسة اللغة، وهي: أولا الممارسة الميكانيكية، ويعني بها أنشطة التحكم التي تنطوي على تكرارواستبدال التدريبات،

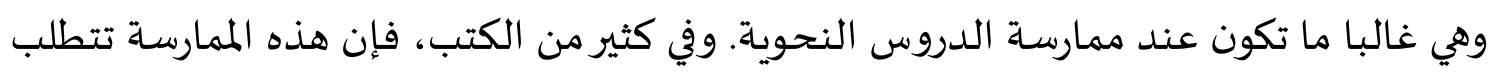
إنجاز جملة (عادة مع الأنشطة النحوي في العزلة)

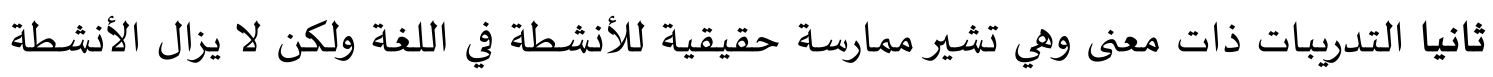
فياه محكمة بحيث يطلب من المتعلمين اتخاذ قرارات ذات معنى عند تنفيذ الممارساة.

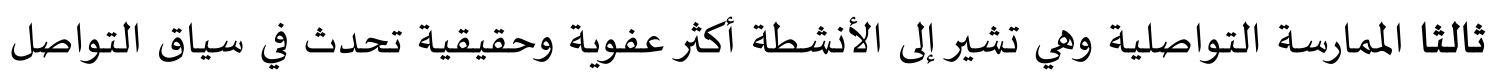

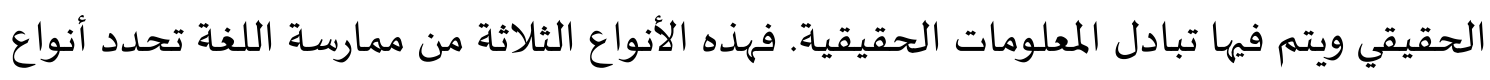

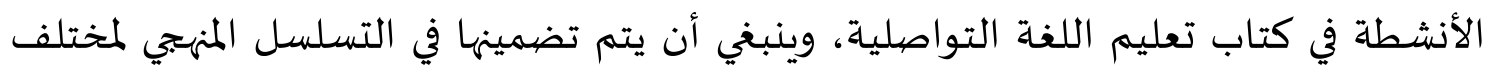
الوحدات التي تشكل الكتاب.

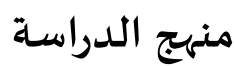

هذه الدراسة دراسة وصفية تحليلية تعتمد على المنهج الكيفي وذلك لتقديم التصيور

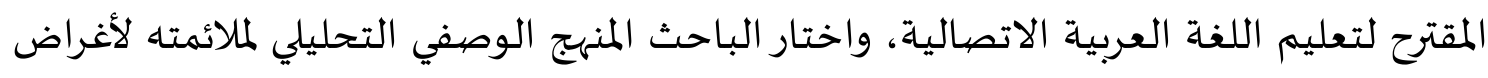

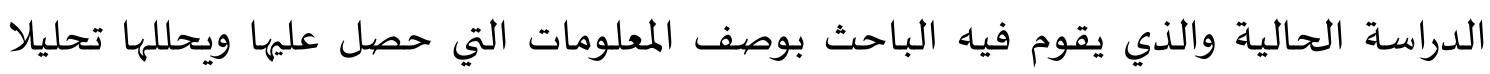

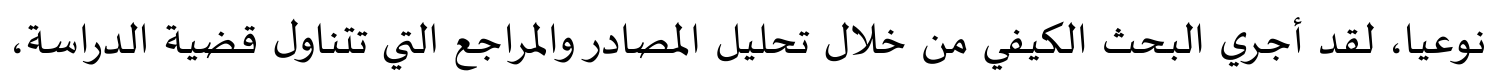

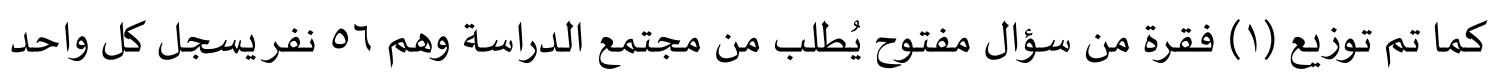

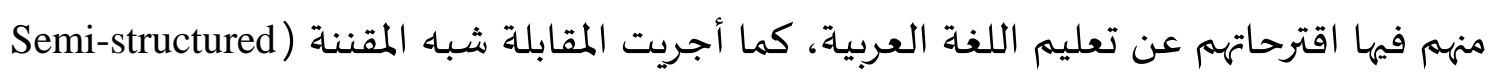


(interview الاتصالي. وتم جمع البيانات وتحليلها بتصفية هذه البيانات عن طريق ترتيب هذه البيانات وتنظيمها وتفسيرها وفقا لمتطلبات الدراسـة.

نتائج الدراسـة مما تم بيانه في الإطار النظري اقترح الباحث أن يكون تعليم اللغة العربية بمدخل اتصالي أن يراعي أربعة جوانب عند تنفيذ عملية التعليم والتعلم، وهي: ا. . جانب البيداغوجيا والذي يتضمن ثلاثة أمور: المدخل والطرق والتقويم. r. جانب الدور الذي يهتم بثلاثة أمور: دور المعلم ودور المتعلم ودور المواد الدراسية. r. جانب تركيز المهارات من الاستماع والكلام والقراءة والكتابة. ع. اهتمامات أخرى تتمثل في أوقات التدريس ووسائل المعلمومات والتكنولوجيا والبيئة. وسيته وصف هذه الجوانب الأربعة بمزيد من التفصيل فيما يلي:

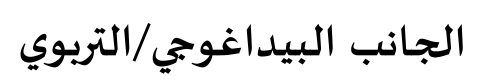

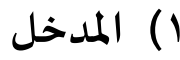

ينبغي الأخذ بعين الاعتبار أن المدخل الاتصالي هو المدخل الذي يركز اهتمامه على مهارات الاتصال الفعال والعملي. وقد اخترق هذا المدخل استراتيجيا جديدا في مجال تدريس اللغة الثانية، ويعتبر هوري بمثاباة مدخل متكامل ويحتوي على خصائص محددة، لأنه مزيت من الاستراتيجيات ويعتمد على

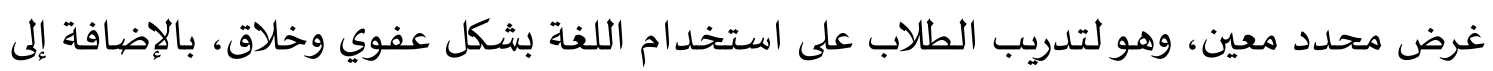
التمكن من قواعد اللغة. وهكذا، فإن مبادئ هذا المدخل تشجع الطلاب على استخدام اللغة العربية.

(r

لتطبيق هذا المدخل ينبغي من توفير الفرص للمتعلمين لاستخدام اللغة العربية في وضع طبيعي وبشكل عفوي وإبداعي، في حين أن التركيز من هذا المدخل هو نقل المعنى أو الغرض بطريقة

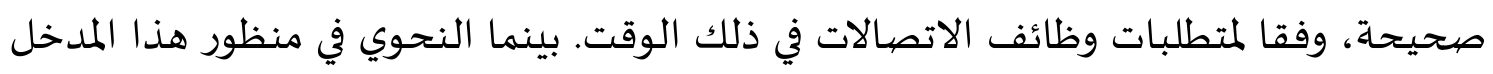
هو مجرد المعرفة لمعنى الجملة ومواضع الكلمات في الجملة، بحيث يقدر المتعلمون على التعبير عن أفكارهم ومشـاعرهم ورغباتهم مع الاستناد إلى قواعد اللغة الصحيحة ومدية. r) التقويم وهو عبارةعن إصدار حكم لتقييم مدى فعالية المدخل الاتصالي والتعرف على ما تحقق من الأهداف المرسومة لله و ما لم يتحقق واقتراح ما يلزم تحقيقه. ويتم ذلك بجمع وتصنيف وتحليل 
وتفسير البيانات والمعلومات كمية كانت أو كيفية عن ظاهرة بقصيد استخداهها في إصدار الحكم والقرار، وبقصد رفع مستوى العملية التعليمية من خلال تشخيص نواحي القوة والضعف.

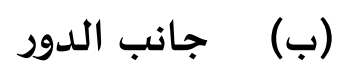

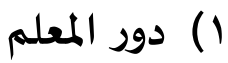

ينبغي الإهتمام أن في المدخل الاتصالي يكون المعلم هو الحافز والمقيم والميسر والمصحح خلال

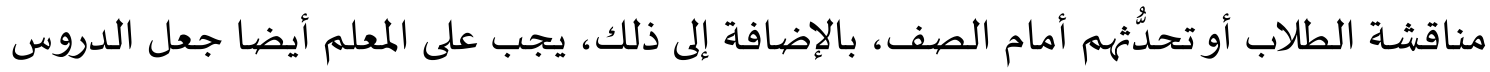

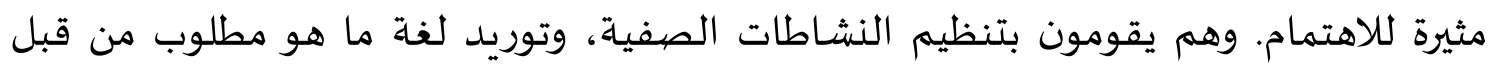
الطلاب أو إشراكهم في الأنشطة التواصلية.

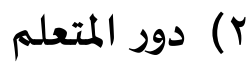
الدور الرئيسي للمتعلمين في تعليم اللغة العربية الاتصالية هو القيام بالاتصال، فلهم دور فعال

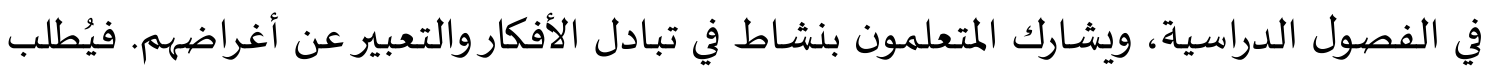
من الطلاب من خلال عملية التعلم التواصل شفويا والاهتمام بجميع مكونات الكفاءة التواصلية.

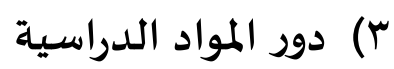

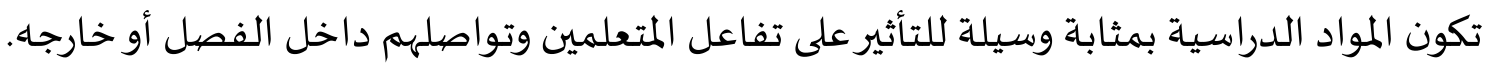

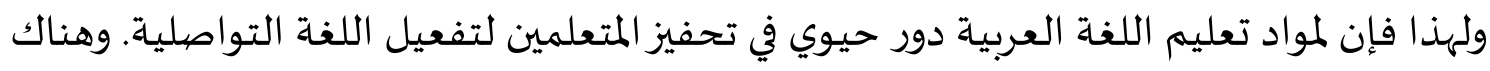

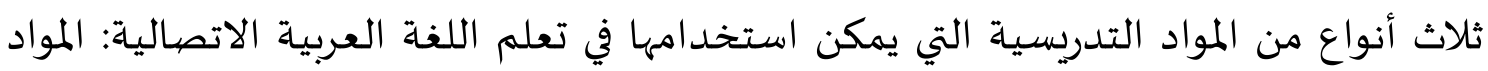

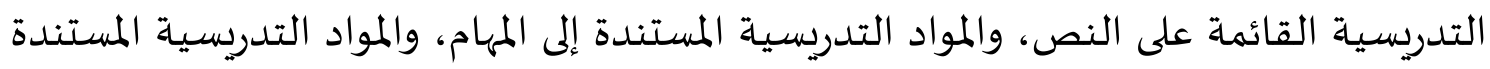

$$
\text { (إلى واقع الحياة. }
$$

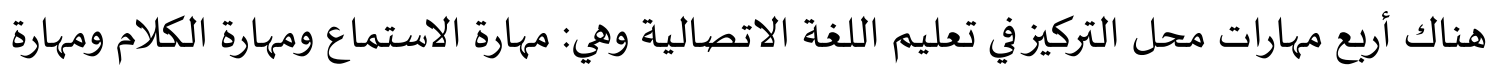

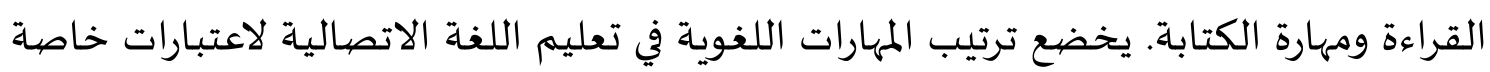

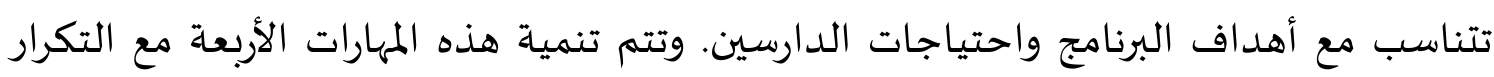

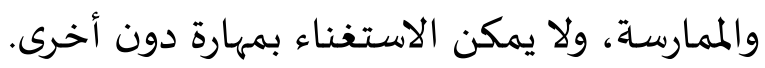

$$
\begin{aligned}
& \text { (د) اهتمامات أخرى } \\
& \text { (1) أوقات التدريس }
\end{aligned}
$$

ومن عناصر الاهتمام في برنامج تعليم اللغة العربية الاتصالية ما يتعلق بأوقات التدريس. كلما

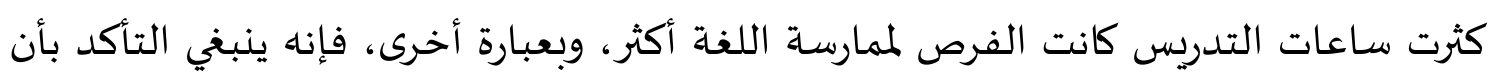

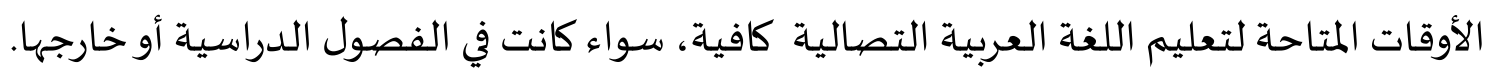

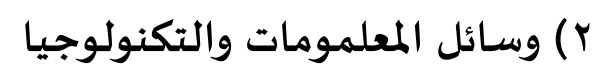


أحد العناصر الهامة في تعليم اللغة العربية الاتصالية استخدام وسائل المعلومات والتكنولوجيا. باستخدام وسائل المعلومات والتكنولوجيا يصبح التعلم أكثر انفتاحا، وإبداعا، فعاليا. بتطوّر

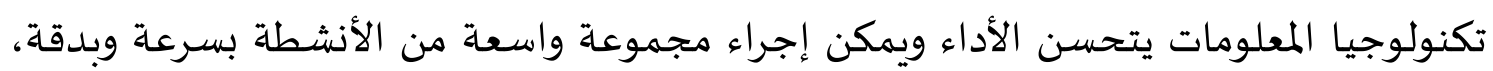
فترتفع الإنتاجية التعليمية في نهاية المطاف.

r) (بئية البئة

ومن أساسيات الداعمة في تحقيق النجاح لعملية تعليم اللغة العبية الاتصالية إنشاء البيئة العربياة، وينبغي إنشاء البيئة التي تشجع المتعلمين على الكلام باللغة العربية من دون الشعور بالخجل والخوف أو الخطأ، وبهذا لا بد أن تكون البيئة العربية ظاهرة مرئية مثل لوحات الكتابات العربية، وأن تكون مشعورة محسوسة مثل التحفيز من المعلم ومواضببة المتعلمين على التكلم باللغة العربية من دون الخجل. وينبغي أن تكون البيئة طبيعية تعكس البيئة اللغوية والثقافية الواقعية للناطقين باللغة.

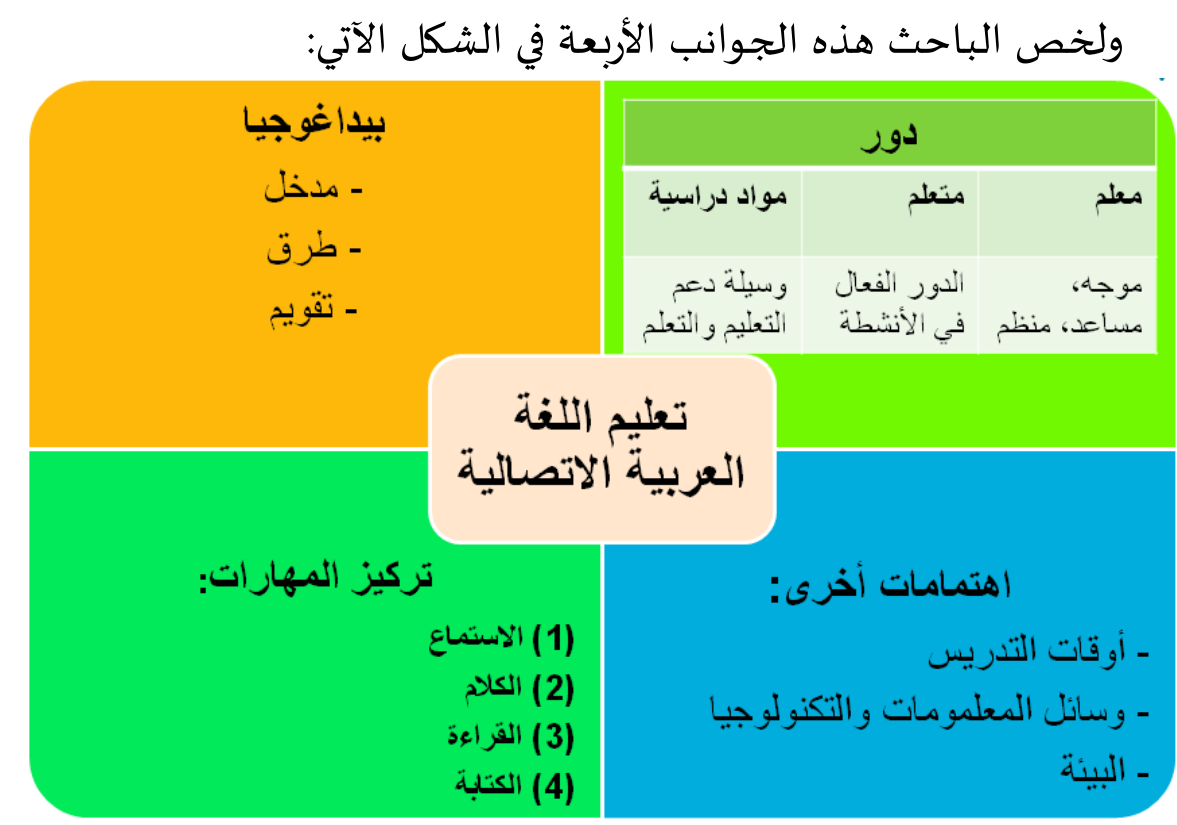

شكل ا: نموذج تعليم اللغة العربية الاتصالية

نموذج كتاب تعليم اللغة العربية الاتصالية

ويقترح الباحث أن يتم تأليف كتاب تعليم اللغة العربية بمدخل اتصالي بما يلي، وهي: (1) من حيث الإعداد

ا. ينبغي أن يعد الكتاب أفراد مجموعة من الخبراء ذووا استعداد خاص وقدرات معينة وتخصص دقيق، وبهذا يمكن إعداد الكتاب على درجة عالية وعلى أسس علمية سليماة ومنظمة. 
r. ينبغي أن يستمد تأليف تعليم اللغة العربية من الأسس العلمية لإعداد المواد التعليمياة، وهي الأسس النفسية والاجتماعية واللغوية والتربوية والثقافياة.

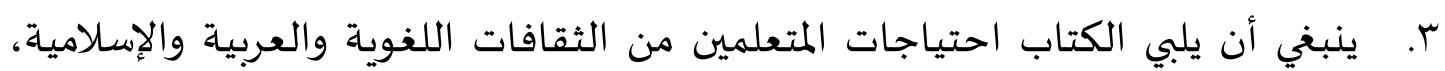
وتنمية المهارات اللغوية الأربع، وهي الاستماع، والكلام، والقراءة والكتابة. ع. ينبغي تجريب الكتاب لاختبار صلاحيته؛ فيعرف من خلال هذا التجريب مواطن الصعوبة

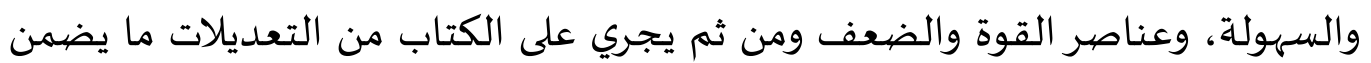
له مستوى أرفع، وما يحقق باه أهدافا أكثر. 0. وأخيرا بعد استخدام الكتاب فينبغي التعرف على نقطة القوة والضعف فحفيه فيه، والتأكد من صلاحية استخدامه لمقرر التعليم. ويركز تقويم الكتاب المدرسي على تحديد كفاية ظاهرتين: الصلاحية والفعالية؛ صلاحية الكتاب المدرسي أو أحد عوامله أو عملياته

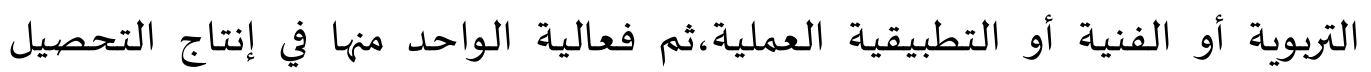
المطلوب.

\section{من حيث مفهوم تعليم اللغة العربية الاتصالية}

في تعليم اللغة الاتصالية يبرز دور المتعلمين في الفصول الدراسية؛ فهم مركز الأنشطة،

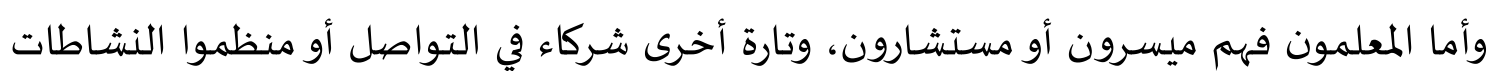
الصفية، وأما المواد الدراسية فهي وسيلة التفاعل بين المتعلمين والمعلمين. فينبغي أن ينطلق تأليف الكتاب لتعليم اللغة العربية الاتصالية من هذا المفهوم، حتى يظهر الكتاب بشكل ما يتناسب مع مبادئ تعليم اللغة العربية الاتصالية.

$$
\text { (r) من حيث الكفاءة والمستويات الدراسية مئدية }
$$

بحيث يعرف الفرد النظام الذي يحكم اللغة، ويطبقه دون انتباه أو تفكير واع، والذي يسمى بالكفاءة اللغوية، ويقدر على استعمال اللغة بشكل تلقائي في مواقف الاستعمال الاتصالي الفعلي، ما يسمى بالكفاياة الاتصالياة.

كما ينبغي تحديد المستويات الدراسية للكتاب ووضع مؤشر خاص يعبر عن مدى تمكن المتعلم من اللغة الهدف في كل مستوى، ويتم تقسيم هذه المستويات مثلا إلى مستوى مبتدئ،

$$
\text { ومتوسط، ومتقدم. من حيث المحتوى المت المن }
$$


وهناك عددا من المجالات العامة للاتصال اللغوي يمكن تضمينها في كتاب تعليم اللغة العربية الاتصالية، ولكل مجال من هذه المجالات بالطبع أنماط اللغة المناسبة لها من أصوات ومفردات

$$
\text { وتراكيب، فضلا عن السياق الثقافي المحيط بها. وهذه المجالات هي: }
$$$$
\text { 1. . تكوين العلاقات الاجتماعية والاحتفاظ بها. }
$$

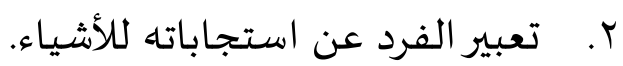$$
\text { r. إخفاء الفرد نواياه. }
$$$$
\text { ع. تخلص الفرد من متاعباء. }
$$$$
\text { 0. طلب المعلومات وإعطاؤها. }
$$

7 7. تعلم طريقة عمل الأشياء أو تعليمها للآخرين. V . المحادثة عبر التليفون. V 1. . حل المشكلات.

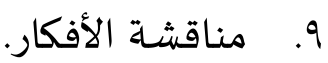
• ا. العب باللغة. 11. لعب الأدوار الاجتماعية. rا. الترويح عن الآخرين. זا. آ تحقيق الفرد لإنجازاته. ع ا. المشاركة في التسلية وإزجاء الفراغ.

ثم ينبغي من تنويع الأنشطة في كتاب تعليم اللغة العبرية الاتصالية. ويمكن تكييف ما

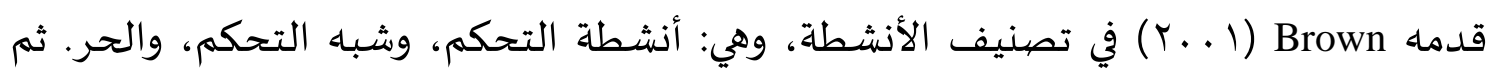
نضع هذه الأنشطة في الموضيوعات المناسبة بالكتاب. وفيما يلي خلاصة للتفصيل السابق: 


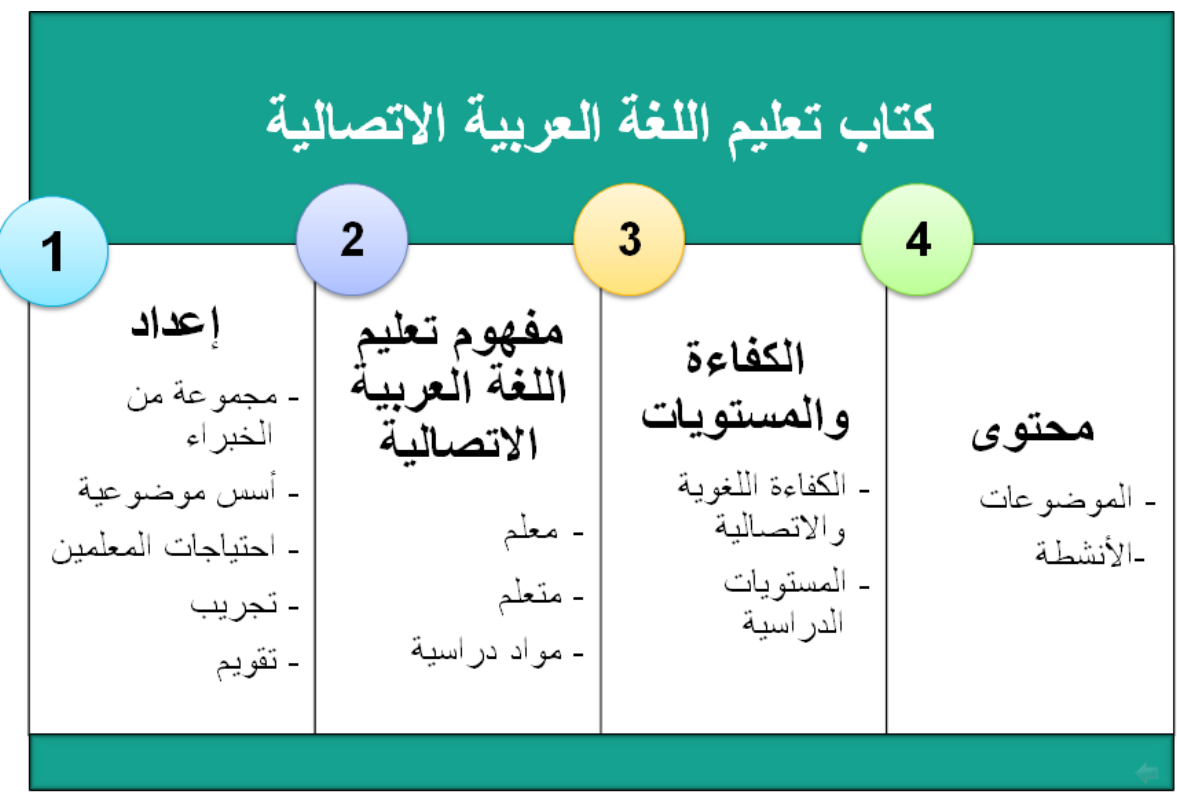

شكل: r نموذج لكتاب تعليم اللغة العربية الاتصالية

نموذج لأنشطة التواصل الشفوي-السمعي لكتاب تعليم اللغة العربية الاتصالية يُقترح أن يكون تصنيف الأنشطة كالآتي: أنشطة التحكم، وشبـا التحكم، والحر. وفيما يلي تفصيل ذلك:

الاعدول ب قائمة الأنشطة التواصلية النموذجية

\begin{tabular}{|c|c|c|}
\hline الأنشطة التي تدمج مهارات الاستماع والتحدث & أنشطة الاستماع فقط & تقنيات \\
\hline الاحماء: الأغاني، والنكات، والألعاب & التنظيم: التعليمات الفصلية المتعلقة بنظامها & \\
\hline تقديم لعب دور: التوضيح الموجز لمحتوى & شرح المحتوى: شرح القواعد النحوية والصرفية & \\
\hline حوار/ قراءة السرد: قراءة نص معد سلفا & وغيرها & \\
\hline القراءة بصوت عال: القراءة مباشرة من النص & التهيئة: التركيز على الموضوع & \\
\hline عرض سؤال وجواب: يرد الطلاب على أسئلة المعلمين. & تقديم الجوار: الاستماع لاستقبال غير نشيط & \\
\hline \multirow[t]{5}{*}{ التدريب: التكرار، والاستبدال مع المعنى القليل المرفق } & الإملاء: حيث يكتب الدارسون نصيّا استمعوا & \\
\hline & & \\
\hline & المراجعة: يقوم المعلم بمراجعة الدرس السابق & \\
\hline & ملخصا له & تقنيات \\
\hline & & 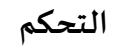 \\
\hline & & \\
\hline & & \\
\hline & & \\
\hline & & \\
\hline & & \\
\hline
\end{tabular}




\begin{tabular}{|c|c|c|}
\hline 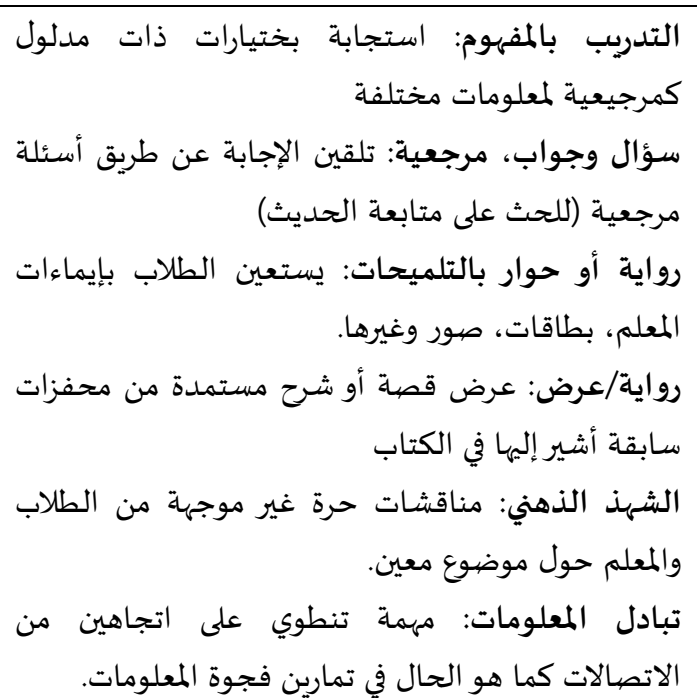 & 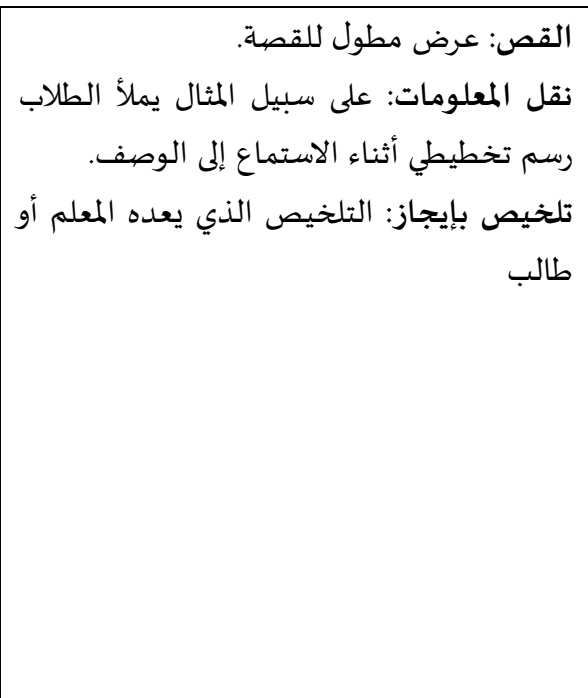 & تقنيات \\
\hline 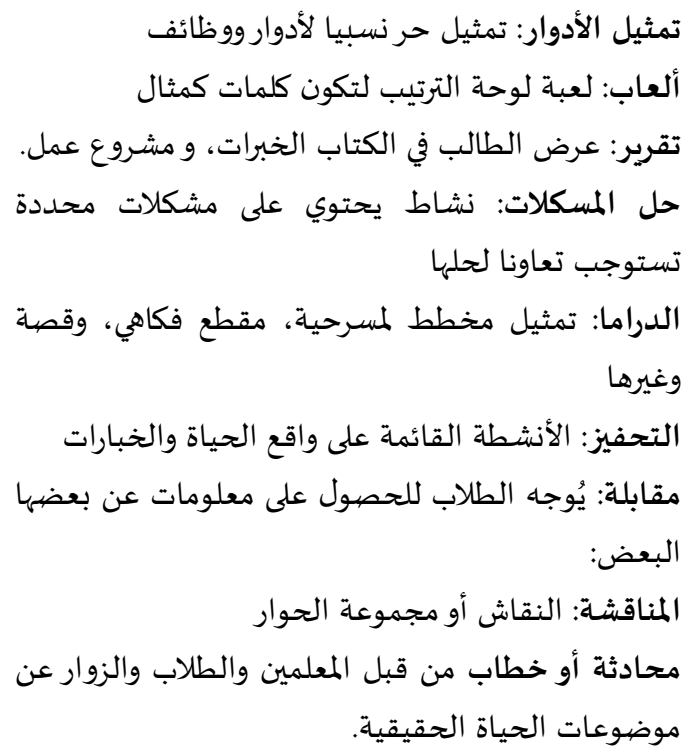 & & تقنيات حرة \\
\hline
\end{tabular}

فهذه الأنواع الثلاثة من الأنشطة يُقترح أن يتم دمجها في كل مستوى من مستويات تعليم اللغة

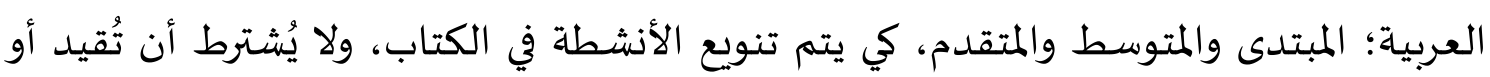
تخصص أنواع الأنشطة بمستوى معين. وفيما يلي خلاصة التفصيل المذكور: 
أنثطة التواصل الثفوي- السمعي المطروحة في الكتاب

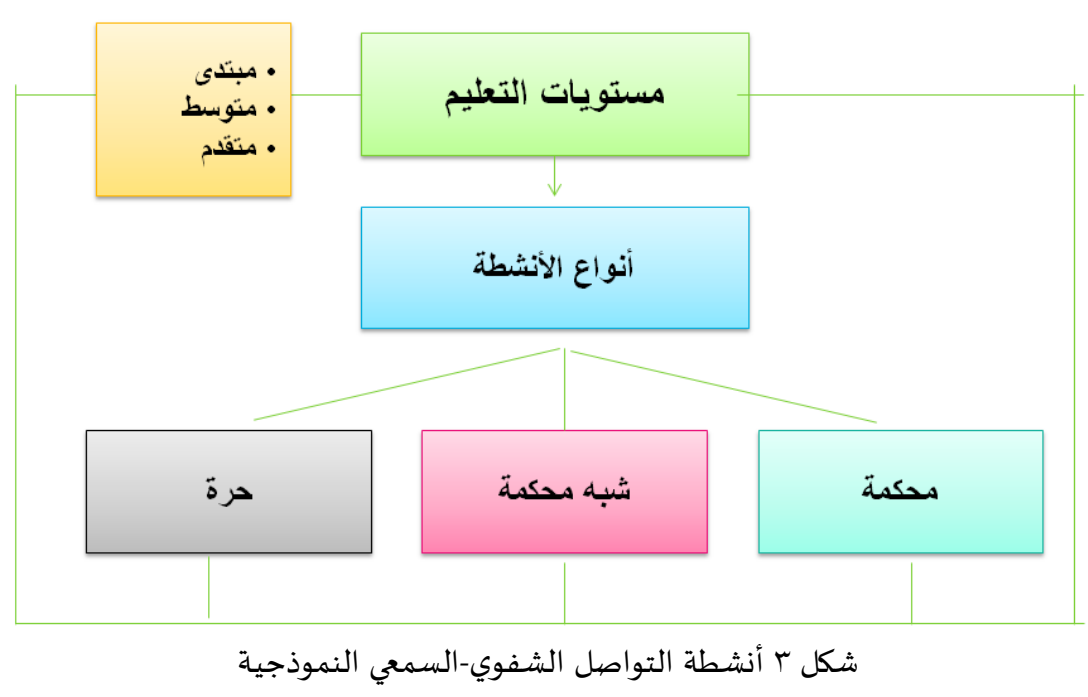

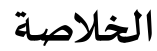

وقد أُجريت الدراسة الحالية لتقديم التصهور المقترح لبرنامج تعليم اللغة العربية الاتصالية. وحاولت الدراسة الحالية الإجابة عن السؤال ما هو التصور المقترح لبرنامج تعليم اللغة

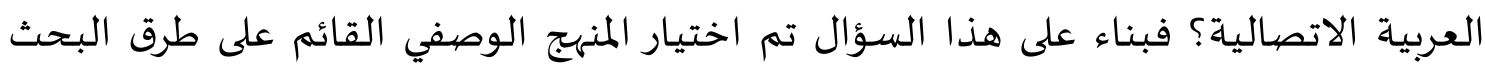

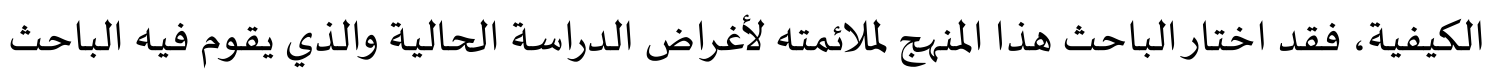

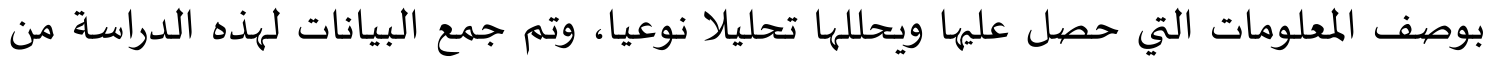
خلال الدراسة المكتبية واستطلاع آراء المدرسين عن طريق المقابلة شبه المقننة. وتوصيّلت هذه المهات

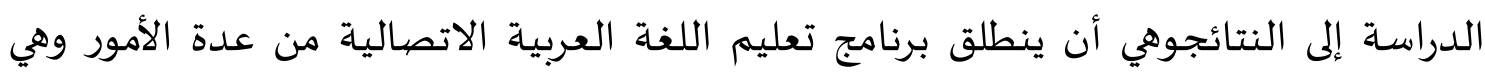

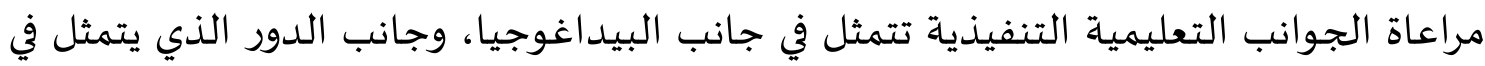

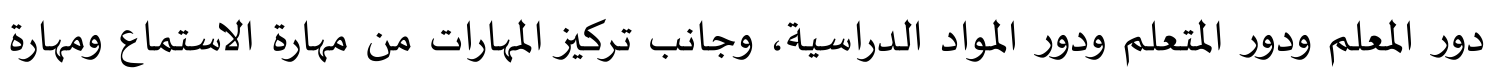

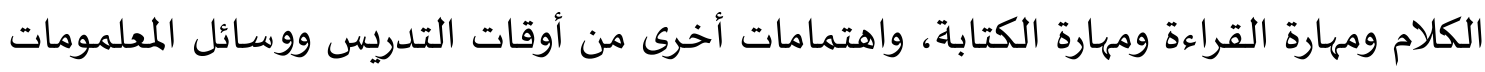

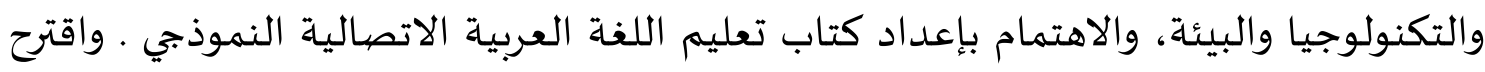

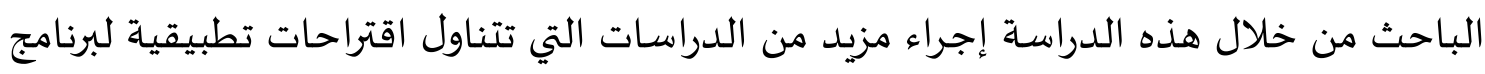
تعليم اللغة العربية بالمدخل الاتصالي.

المراجع والمصيادر 


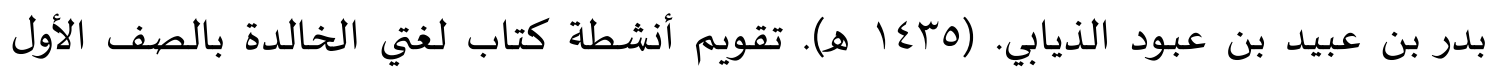
المتوسط في ضوء مهارات الاستماع المناسبة للتلاميذ. رسالة ماجستير. كلية التربية جامعة

$$
\text { أم القرى. }
$$

جمال عبد الناصر زكريا. (17 (Y). المدخل إلى تدريس اللغة العربية للناطقين بغيرها طرائق ومفاهيم. كوالا لمبور: الجامعة الإسلامية العالمية بماليزيا للنشر.

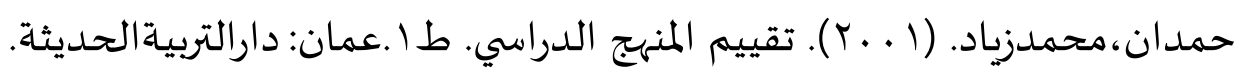
طعيمة، أحمد رشدي. (1919). تعليم العربية للناطقين بها. مصرئ جامعادة المنصورة. طعيمة، أحمد رشـدي. (YNA)). الأسس المعجمية والثقافية لتعليم اللغة العربية لغير الناطقين مها. مكة المكرمة. جامعة أم القرى وحدة البحوث والمناهج سلسلة دراسات في تعليم اللغة

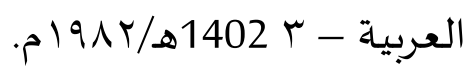

طعيمة، أحمد رشـدي. (د. س). المرجع في تعليم اللغة العربية للناطقين بلغات أخرى. جامعة أم أم

$$
\text { القرى. مطابع جامعة أم القرى. أحمان. }
$$

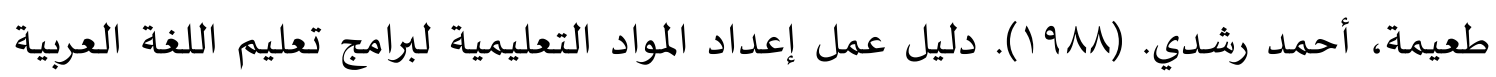
للناطقين بلغات أخرى.مكةالمكرمة. جامعة أمالقرى.

طعيماة، أحمد رشـدي. (1991).مناهج تدريس اللغةالعربية بالتعليم الأساسي. القاهرة. دارالفكر العربي.

طعيمة، أحمد رشدي. ( . . . . الأسس العامة لمناهج تعليم اللغةالعربية. القاهرة.دارالفكرالعربي.

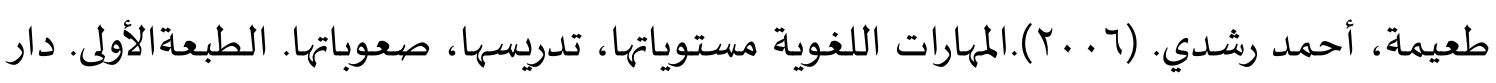

$$
\text { الفكرالعربي: القاهرة. }
$$

طعيمة، أحمد رشدي. (ع . . (Y). الأسس العامة لمناهج تعليم اللغة العربية إعدادها-تطويرها-

$$
\text { تقويمها. القاهرة. دار الفكر العربي. }
$$

طعيماة، أحمد رشـدي و مناع، محمد السيد. (1 . . ( ). تدريس العربية في التعليم العام نظريات

$$
\text { وتجارب. القاهرة: دار الفكر العربي. }
$$

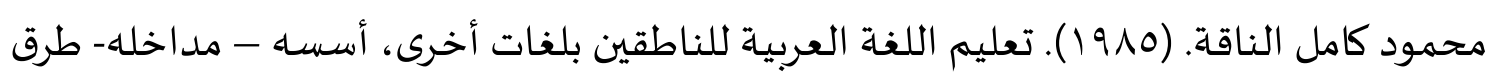

$$
\text { تدريسهة. مكة المكرمة: جامعة أم القرى. }
$$

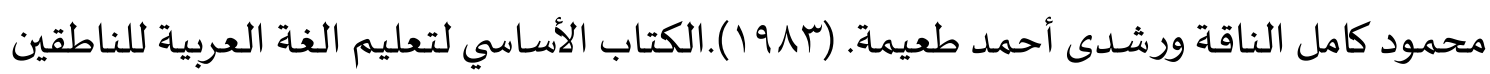

$$
\text { بلغات أخرى إعداده - تحليله - تقويماه. مكةالمكرمة. جامعة أم القرى. }
$$

Ali Algonhaim (2014). Saudi University Students' Perception and Attitudes Towards Communicative and Non-Communicative Activities and Their Relationship to Foreign Language Anxiety. Research Journal of English Language and Literature 
(RJELAL) A Peer Reviewed International Journal - Http://www.rjelal.com,2(2), 83101.

Beale, J. (2002). Is Communicative Language Teaching a Thing of The Past? Babel, Vol. 37, No. 1, Winter 2002, pp. 1216.http://www.jasonbeale.com/essaypages/clt_essay.html. [16 september 2014]

Brown, H. D. (2001). Teaching by Principles. An Interactive Approach to Language Pedagogy. $2^{\text {nd }}$ Ed. New York. Longman Press. P. 133-136.

Creswell, J. (1998). Qualitative Inquiry and Research Design: Choosing Among Five Traditions. London: SAGE Publications.

Cunningsworth, A. (1984). Evaluating and selecting EFL teaching materials. London: Heinemann Educational Books.

Cunningsworth, A. (1995). Choosing your coursebook. Oxford, Heienemann.

Littlewood, W. (1981). Communicative language teaching. New York: Cambridge University.

Littlewood, W. (1983). Communicative Language Teaching. An Introduction. New York. Cambridge University Press.

Murphy, J. (1991). Oral Communication in TESOL: Integrating Speaking, Listening and Pronunciation. Tesol Quarterly. Vol. 25, no. 1, Spring 1991.

Neuman, W.L. (2000). Social Research Methods: Qualitative and Quantitative Approaches. Needham Heights: Allyn an Bacon.

Nunan, D. (1999). Designing Tasks for the Communicative Classrom. Cambridge. Cambridge University Press.

Richards, J. \& Rogers, T.S (1986). Approaches and Methods in Language Teaching: A Description and Analysis. Cambrige: Cambridge University Press.

Richards, J. C. (1993). Beyond the text book: The role of commercial materials in language teaching. RELC Journal, 24(1). http://dx.doi.org/10.1177/003368829302400101

Zaky Hassan Sayyed Ahmed Abu El-lif. (2012).An Evaluation of the Oral/Aural Activities in the Saudi Third Year Secondary EFL Textbooks. Ph.D Thesis unpublished. Universiti Kebangsaan Malaysia.

Zohrabi, M., Sabouri, H., \& Behroozian, R. (2012). An evaluation of merits and demerits of Iranian first year high school English textbook. English Language Teaching, 5(8), 14-22. http://doi.org/10.5539/elt.v5n8p14 diakses pada 19/11/15.

Abdul Rahman Abdullah. (2009). Kompetensi komunikatif dan strategi komunikasi Bahasa Arab di kalangan pelajar Sekolah Menengah Kebangsaan Agama di Negeri Selangor. Tesis Ph.D. Universiti Malaya.

Aladdin, A. (2012). Analisis penggunaan strategi komunikasi dalam komunikasi lisan Bahasa Arab.GEMA: Online Journal of Language Studies. Retrieved from http://journalarticle.ukm.my/4936/.

Gamal Abdul Nasir Zakaria, Salwa Mahalle, \& Aliff Nawi. (2015). Kajian Amalan Pengajaran Guru Bahasa Arab Sekolah Menengah di Negara Brunei Darussalam.Q-jIE The Online Journal of Islamic Education, 3(1), 32-40.

Kamarul Shukri Mat Teh, Nik Mohamad Rahimi, Mohd Amin Embi dan Zambri Mahamod. (2009). Hubungan Penggunaan Strategi Pembelajaran Bahasa dengan Tahap Pengguasaan Bahasa Arab. Journal of Islamic and Arabic Education. Vol. 1(1), 41-46. 
Nasimah Hj. Abdullah. (2006). Permasalahan dalam Pembelajaran bagi Pelajar Diploma Pengajian Islam (Bahasa Arab) di KUIS dan Cara Mengatasinya. Prosiding Wacana Pengajian Islam, Siri 5, 199-208.

Nik Mohd Rahimi bin Nik Yusoff (2005). Penilaian Kemahiran Mendengar Dalam Kurikulum Bahasa Arab Komunikasi di Sekolah-Sekolah Agama Kerajaan Negeri. Tesis Ph.D. Tidak diterbitkan. Bangi: Universiti Kebangsaan Malaysia.

Noorhayati Hashim (2009). Keberkesanan Kaedah Noor Dalam Pengajaran Dan P Pembelajaran Nahu Bahasa Arab. Tesis Doktor Falsafah Pendidikan. Kuala Lumpur:UniversitiMalaya.

Samah, R., Abdul Hamid, M. F., Hafes Sha'ari, S., \& Helmi Mohamad, A. (2013). Aktiviti pengajaran kemahiran bertutur bahasa Arab dalam kalangan jurulatih debat. GEMA Online Journal of Language Studies, 13(2), 99-116.

Zawawi Ismail, Ab Halim Tamuri, Nik Mohd Rahimi Nik Yusoff dan Mohd Ala-uddin Othman. (2011). Teknik kemahiran bertutur Bahasa Arab di SMKA Malaysia. اوككل رفو.82-82), 